Article

\title{
Accumulation Mechanism and Effects of Naturally Occurring Radioactive Materials in the Filters of Bottled Mineral-Water Facilities
}

\author{
Woosik Shin ${ }^{1}$, Jina Jeong ${ }^{2}$, Jeong-Hee Han ${ }^{1}$, Byung-Uck Chang ${ }^{3}{ }^{(0)}$ and Sungwook Choung ${ }^{1, *}$ (i) \\ 1 Research Center for Geochronology and Isotope Analysis, Korea Basic Science Institute (KBSI), \\ Cheongju 28119, Korea; sws3286@kbsi.re.kr (W.S.); hanjh@kbsi.re.kr (J.-H.H.) \\ 2 Department of Geology, Kyungpook National University, Daegu 41566, Korea; jeong.j@knu.ac.kr \\ 3 Korea Institute of Nuclear Safety (KINS), Daejeon 34142, Korea; hafadai@kins.re.kr \\ * Correspondence: schoung@kbsi.re.kr; Tel.: +82-43-240-534; Fax: +82-43-240-5319
}

Received: 24 February 2020; Accepted: 19 March 2020; Published: 25 March 2020

\begin{abstract}
Groundwater contains naturally occurring radioactive materials (NORMs) through water-rock interactions. Although a recent study found that the NORMs are accumulated into the filters utilized in bottled mineral-water facilities, the accumulation mechanism and effects have rarely been studied. This study is, therefore, conducted to determine the mechanism of NORM accumulation in filters during water treatment processes and to provide a first estimate of the level of radiological risk for workers in five bottled-mineral-water facilities. The level of $\mathrm{Rn}$-222 decreased dramatically at the first filters (FF) encountered after passing through water storage tanks, while surface radiation sharply increased. The increase of radioactivity on the FF was mainly caused by the accumulation of short-lived radon progenies through decay processes inside the water tanks. Although the estimated radiological risk was lower under certain circumstances compared to the public dose limit of $1 \mathrm{mSv} \mathrm{yr}^{-1}$, the radiological risk should be properly managed in case of direct and/or close handling of the used filters during filter replacement procedures.
\end{abstract}

Keywords: naturally occurring radioactive materials; bottled-mineral-water facility; accumulation mechanism; filter; radiological risk

\section{Introduction}

Groundwater that has been used as a source of drinking water could contain naturally occurring radioactive materials (NORMs) such as uranium, radium, and radon through long time-scale water-rock interactions. Numerous studies have investigated their occurrences and geological relationships in the groundwater environments [1-6], as well as health risks via water ingestion [7-9]. Recent studies have begun to focus on the accumulation of NORMs in byproducts of the groundwater treatment process, such as sludge and sediments [10-16].

The accumulation mechanisms and effects of NORMs (e.g., health risk by external radiation) are, however, rarely studied due to typically low concentration of radionuclides in groundwater. In the case of bottled-mineral-water facilities, relatively deep groundwater is filtered using membrane filters (MFs) and activated carbon filters (ACFs). A variety of micro-sized MFs is used as the main filters in many bottled-mineral-water facilities. Because of the low removal efficiency of radionuclides by MFs and ACFs $[17,18]$, it is expected that NORMs are unlikely to accumulate in the MFs and ACFs. However, high surface radiation dose rates on filter housings observed in our previous study [19] indicated the potential accumulation of NORMs in MFs and ACFs. Considering that the MFs and ACFs are the predominant byproducts in the bottled-mineral-water facilities, the accumulation mechanism 
of NORMs into filters and its effects must be determined to reduce the health risk to workers in such facilities.

This study is, therefore, carried out to determine the accumulation mechanism of NORMs in filters that are used for water treatment processes in bottled-mineral-water facilities, and to evaluate the radiological risk for workers in the water facilities and/or filter-waste disposal sites. In addition, the specific objective of this study is to suggest the proper management methods that could reduce the risk for workers related to the NORM-concentrated filters.

\section{Materials and Methods}

\subsection{Study Sites}

Five bottled-mineral-water facilities in South Korea are investigated. All facilities are located in rural areas to prevent anthropogenic contamination. Any detailed information on these facilities, such as the bottled-mineral-water brand and geographical locations, are not provided at the behest of companies. All facilities are placed on the Precambrian gneiss bedrock, although the degree and age of metamorphism vary. Each facility has several wells to pump groundwater out, and the well depth ranges from approximately 130 to $250 \mathrm{~m}$ below the surface.

The groundwater treatment procedures usually consist of several filtering steps from wells to the final water products (Figure S1 in the Supplementary Materials). In brief, the groundwater is first filtered using a pre-filter to remove coarse particles such as sediments, soils, and rock fragments, and stored at a raw water storage tank. Then, the tank water goes through various types of MFs and ACFs to produce the bottled mineral water. The MFs were mainly made of hydrophilic polyethersulfone (PES) membrane with highly porosity, and their pore size ranged from 0.2 to $5.0 \mu \mathrm{m}$. The weight of the individual MF was about 2-300 g, and approximately $30 \mathrm{MF}$ cartridges were placed inside the filter housing. The ACFs were installed at all investigated facilities to capture heavy metals, volatile organic chemicals, and odors from groundwater [7]. They are mainly utilized as the pre-filter or first filter (FF) except at $C$ facility (i.e., second filter). The granular type ACFs are replaced once a year at the B, C, D, and E facilities, while 2-3 months for the cartridge type ACF in the A facility. In the case of MFs, they were typically replaced every 3-6 months, depending on the filter conditions.

\subsection{Sampling and Field Measurements}

A series of water samples were collected at each filtering step to evaluate the changes of radioactivity through water treatment processes, and surface radiation dose rates were measured on the filtering unit housings in all investigated facilities. Although the field campaigns were mostly carried out prior to the filter replacement, additional investigations were conducted to consider the effects of filter replacement in A, B, and C facilities. Some of the used filters were collected to analyze the remaining radionuclides in our laboratory.

The groundwater was pumped out for at least 5-10 min before sampling to remove stagnant water in the well and pipelines. Then, $2-4 \mathrm{~L}$ water was sampled without air bubbles to analyze gross $\alpha$ and gross $\beta$ and radium isotopes. For analysis of $\mathrm{Rn}-222$ radioactivity, $15 \mathrm{~mL}$ water was collected into a narrow-neck glass bottle containing $5 \mathrm{~mL}$ of mineral oil as a cocktail solution (High Efficiency Mineral Oil Scintillator, PerkinElmer, USA). In addition, the water samples were acidified below $\mathrm{pH} 2$ to measure the concentrations of uranium and thorium, after filtered by $0.45 \mu \mathrm{m}$ acetate membrane filter (Whatman, Hercules, USA). All samples were stored at $4{ }^{\circ} \mathrm{C}$ in the dark and delivered to the laboratory within $24 \mathrm{~h}$.

The surface radiation dose rates and their gamma spectra were measured at a distance of $0.1 \mathrm{~m}$ from filter housings to determine the external radiation from individual filtering units, using a portable instrument of 2- (LUDLUM SURVEY METER, 44-10 gamma scintillation) and 3-inch NaI detectors (Alpha Spectra Inc., 1211/3). Although the 2-inch NaI detector measured the total external radiation 
level at the surface of each filter, the 3-inch $\mathrm{NaI}$ detector was utilized to determine the individual radionuclides emitted through the stainless steel housing.

\subsection{Laboratory Analyses for Water and Filter Samples}

The detailed procedures on the pre-treatment and analysis of collected water and filter samples were given in our previous study [19]. In brief, total $U$ and Th in the water were analyzed using inductively coupled plasma mass spectroscopy (iCAP Q, Thermo Scientific, USA). The radioactivity of gross $\alpha$ in water was computed by subtracting the uranium concentration in water from the activity of total $\alpha$ that was measured by an ultra low-level liquid scintillation counter (LSC) (Quantulus 1220, Perkin Elmer, USA). The level of Rn-222 in water was also analyzed using the LSC. The gross $\beta$ activity in water was measured using a gas-flow proportional counter (Series 5XLB, Canberra, USA). The radioactivity of Ra-226 and Ra-228 was measured for $24 \mathrm{~h}$ using well-type high purity germanium (HPGe) detector (GCW3523, Canberra, USA) at the peak of Pb-214 (295.2 and $352 \mathrm{keV})$, Bi-214 (609.3 keV), and Ac-228 (338.3 and $911.1 \mathrm{keV})$, respectively.

Prior to the measurements of radionuclides in used filters, the used filters were cut to $10 \times 10 \mathrm{~cm}$ dimensions. The cut fragments were dried and transferred into $1 \mathrm{~L}$ Marinelli beaker, and then the radioactivity of $\mathrm{Pb}-210$ and Th-234 were measured using a well-type HPGe gamma detector. The radioactivity of Po-210 in the used filters was analyzed by an alpha spectrometer (7400-14, Canberra, USA) [20] after sequential pretreatment such as the digestion of samples, recovery of Po-210, and deposition on a silver disc. The concentrations of total uranium and thorium in the used filters were analyzed using ICP-MS after pretreatment of filter samples by the dry-ashing method [21,22].

\subsection{Preliminary Estimation of Radiological Risk}

The potential radiological risk was estimated for the workers in the bottled-mineral-water facilities and used-filter disposal site. The direct exposure to $\gamma$-ray emitted by the NORM-concentrated filters and average working time $\left(W_{T}\right)$ of $4 \mathrm{~h}$ a day within $d_{x}=1 \mathrm{~m}$ distance from the filters were presumed for both cases. For the bottled-mineral-water facility workers, the radiological risk was computed using the modified inverse square law of Equation (1), which reflects the attenuation of radiation by distance in the air $[23,24]$ and exposure frequency.

$$
\operatorname{Risk}_{F}\left[m S v y r^{-1}\right]=I_{0} \times\left(\frac{d_{0}}{d_{x}}\right)^{2} \times \mathrm{W}_{T} \times \mathrm{A}_{T}
$$

where Risk $k_{F}$ is the potential radiological risk for workers at the bottled water facilities. $I_{0}\left(\mu \mathrm{Sv} \mathrm{h}^{-1}\right)$ is the measured radiation dose rate at $d_{0}=0.1 \mathrm{~m}$ distance from the filters. $A_{T}$ is the annual working time (250 days $\mathrm{yr}^{-1}$ ).

In the case of the workers at the used-filter disposal site, the potential risk was determined through annual total radioactivity from the used filter piles. The annual radioactivity $\left(C_{i, A}(\mathrm{MBq})\right)$ was estimated using the radioactivity of individual radionuclides measured in the used filters, filter waste masses and numbers, and filter replacement frequency. The assumption is that the filter wastes were generated for 1 year in a bottled-mineral-water facility, and they were piled in the same disposal site. The estimated annual radioactivity was converted to the effective radiation dose rate as follows:

$$
R_{D}\left[\mu S v y r^{-1}\right]=\sum_{i} \frac{C_{i, A} \Gamma}{d x^{2}} W_{T} A_{T}
$$

where $R_{D}$ is the potential radiological risk for the workers at a used-filter disposal site. $\Gamma$ $\left(\mu \mathrm{Sv} \mathrm{m} \mathrm{m}^{2} \mathrm{~h}^{-1} \mathrm{MBq}^{-1}\right)$ is the gamma constants for individual radionuclides [25]. 


\section{Results and Discussion}

\subsection{Changes of NORM Levels in the Water Filtering Processes}

Most of naturally occurring radionuclides, including gross $\alpha, \beta$, and radium isotopes, were below the detection limit except uranium and Rn-222. Although the uranium concentrations in raw groundwater were significantly different depending on the pumping well locations even in the same facility, they consistently declined to the low level of $\leq 30 \mu \mathrm{g} \mathrm{L}^{-1}$ after the water filtering processes. In particular, the ACF contributed to the decrease of uranium irrespective of filter location [19].

The Rn-222 levels were lowered by at least $>30 \%$ in the raw water storage tank (Figure 1a), because a large air volume and long water residence time in the tank governs the gaseous radon decay processes [19]. In brief, raw water pumped from several groundwater wells slowly fills the tanks. Only about two-thirds of the total tank volume is occupied by water; the other third is usually left vacant at all investigated facilities. The aqueous-phase radon is vaporized to the air of the tanks, and is continuously collapsed to its daughter nuclides, such as polonium, bismuth, and lead $\left(t_{1 / 2}=3.8\right.$ days for $\mathrm{Rn}$-222). Therefore, the $\mathrm{Rn}-222$ radioactivity level in the water rapidly declines in the tanks, and the natural increase of daughter nuclides is expected. In addition, the changes in radon concentrations were rarely associated with the filtering processes, showing inconsistent tendency after the new filter replacement at the $A, B$, and $C$ facilities (Figure $1 b-d$ ).
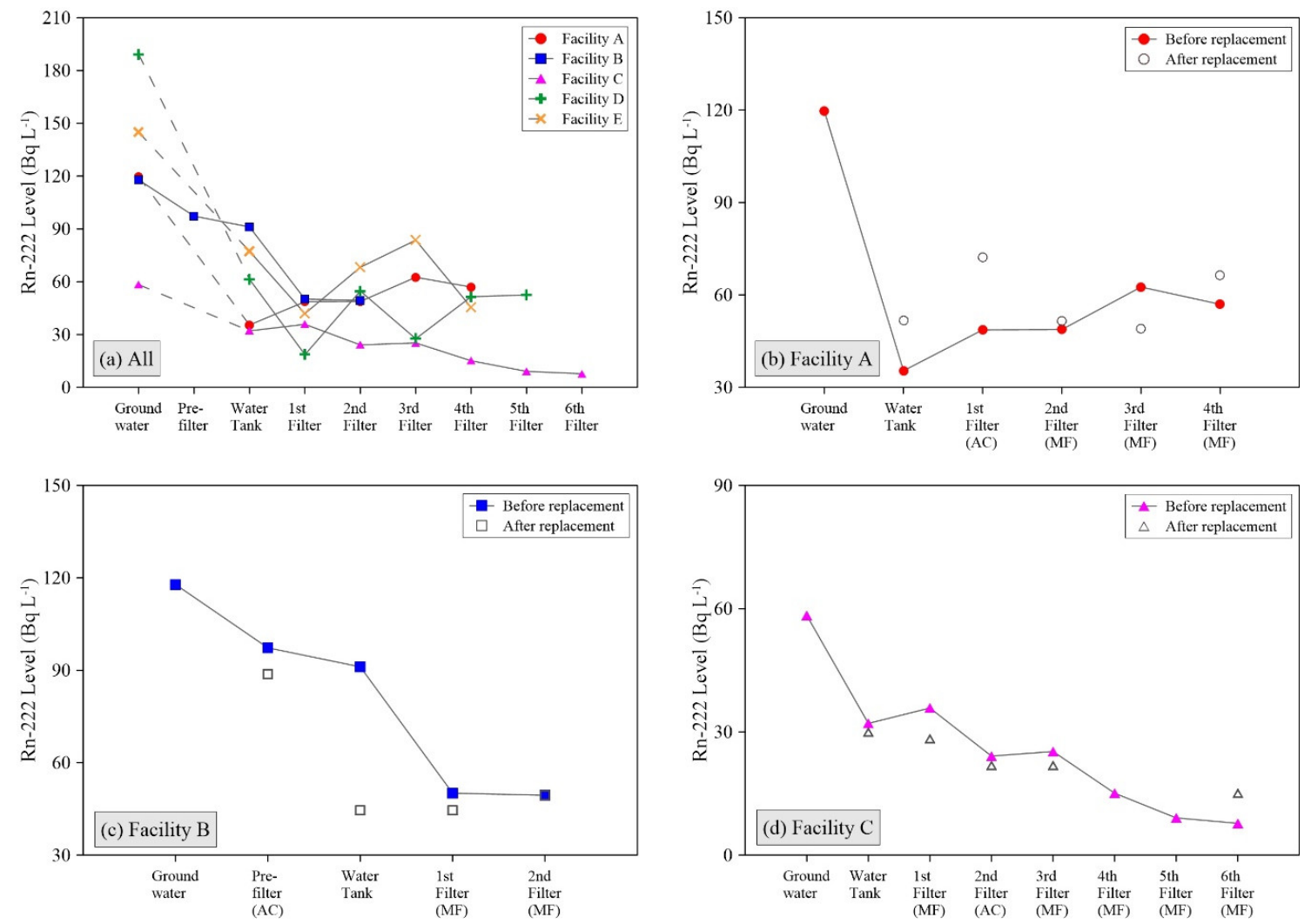

Figure 1. Changes in Rn-222 levels through the water treatment processes: (a) All facilities, (b) Facility A, (c) Facility B, and (d) Facility C. The dashed lines in the upper left figure indicate no filters or equipment in the relevant facilities.

\subsection{Changes of Surface Radiation Dose Rate in the Filters}

The radiation dose rate on the surface of individual filter housings increased dramatically up to $5.25 \mu \mathrm{Sv} \mathrm{h}{ }^{-1}$ at the FF placed right after the water storage tanks regardless of filter types, and then declined to an approximately background level of $<-0.25 \mu \mathrm{Sv} \mathrm{h}^{-1}$ at the next filters (Figure 2a). 
After the water filters were replaced with brand new ones, a sharp decrease of surface radiation was observed, especially for the FFs, compared to the previous levels in the investigated A and C facilities (Figure $2 b, d$ ). The FFs, therefore, can play a key role in the removal of the NORMs from water, and its implication is the accumulation of NORMs inside the FFs.
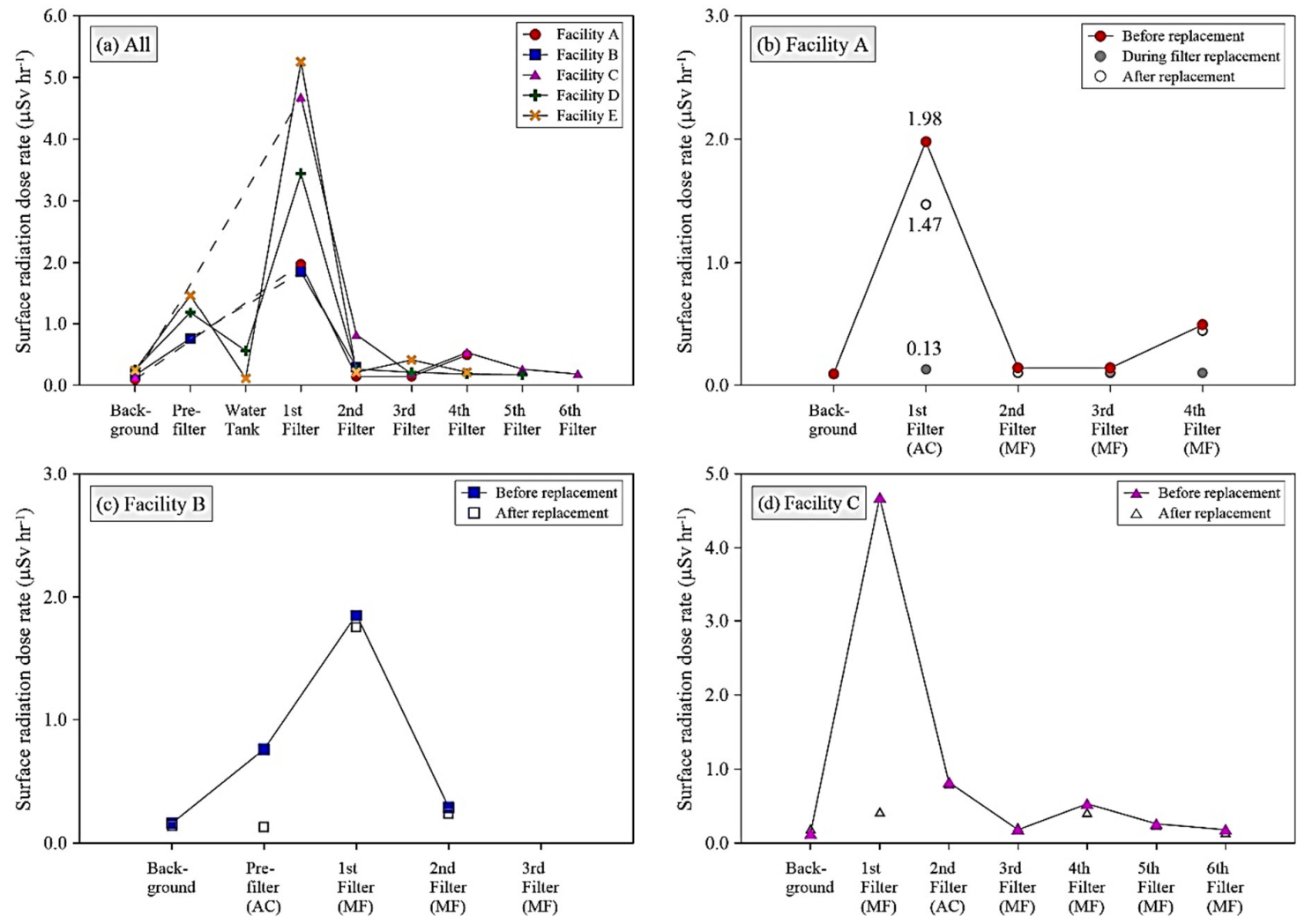

Figure 2. Changes in the surface radiation dose rate through the water treatment processes at individual bottled mineral-water facilities: (a) All facilities, (b) Facility A, (c) Facility B, and (d) Facility C. Surface radiation dose rate was measured at a distance of $0.1 \mathrm{~m}$ from the filter housing. The dashed lines in the upper left figure indicate no filters or equipment in the relevant facilities.

However, after the new filter installation, the recovery of decreased surface radiation dose rates in the FFs depend on the filter conditions and water treatment capacities in individual facilities. The FF of Facility A exhibited a highly restored surface radiation dose rate in a few days after restarting the water filtering operations, while no recovery was observed at the FF of Facility $\mathrm{C}$. This could be associated with the filter types of ACFs and 5- $\mu \mathrm{m}$ MFs that were utilized at the Facilities A and C, respectively, because the $\mathrm{AC}$ materials are more chemically reactive with the dissolved radionuclides than the MFs [17]. Thus, relatively rapid accumulation of the NORMs can occur in the ACF. Although the AC pre-filter of Facility B still indicated low surface radiation dose rate after a few days from filter replacement (Figure 2c), the ACFs were granular type unlike the cartridge filter used in Facility A. The cartridge type ACF may be saturated faster than the granular type ACF, considering that the AC material contents of cartridge type are smaller than granular type under analogous weight conditions. Most importantly, the daily water treatment capacities of Facility A was approximately 2.6 times greater compared to Facility B (more descriptions in the Supplementary Materials).

All individual spectra of gamma radiations measured by the 3-inch NaI detector at Facilities B, C, $\mathrm{D}$, and $\mathrm{E}$ showed the presence of short-lived radon progenies, including Pb-214 and Bi-214 (Figure 3). The strong intensities of these radon progenies' peaks for the FFs are consistent with the decrease phenomena of Rn-222 through decay in the water storage tanks (Figure 1). In addition, high levels of $\mathrm{Pb}-210$ were observed for the used FFs at the A and C facilities (max. concentration was up to 
$30.0 \mathrm{~Bq} \mathrm{~g}^{-1}$ in Figure 4). This radioactivity of $\mathrm{Pb}-210$ exceeded $22 \mathrm{~Bq} \mathrm{~g}^{-1}$ of the clearance levels for solid materials in indoor storage facilities [26]. These results support that radon decay processes in the water tanks significantly influence the elevation of surface radioactivity and accumulation of NORMs in the FFs because $\mathrm{Pb}-210$ is a decay product of $\mathrm{Pb}-214$, and Bi-214 and heavy metal contents are rarely found in the raw groundwater.
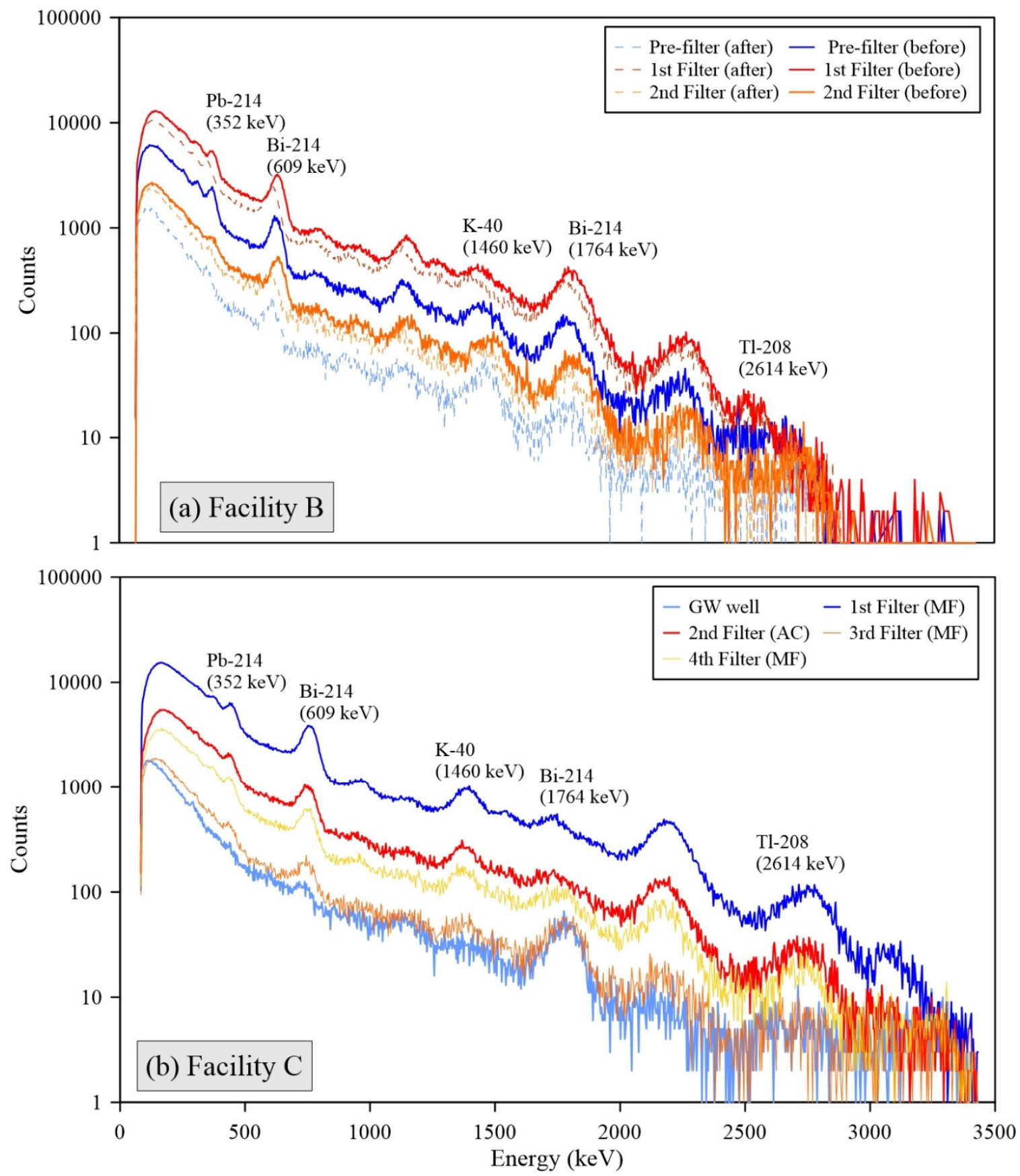

Figure 3. Cont. 

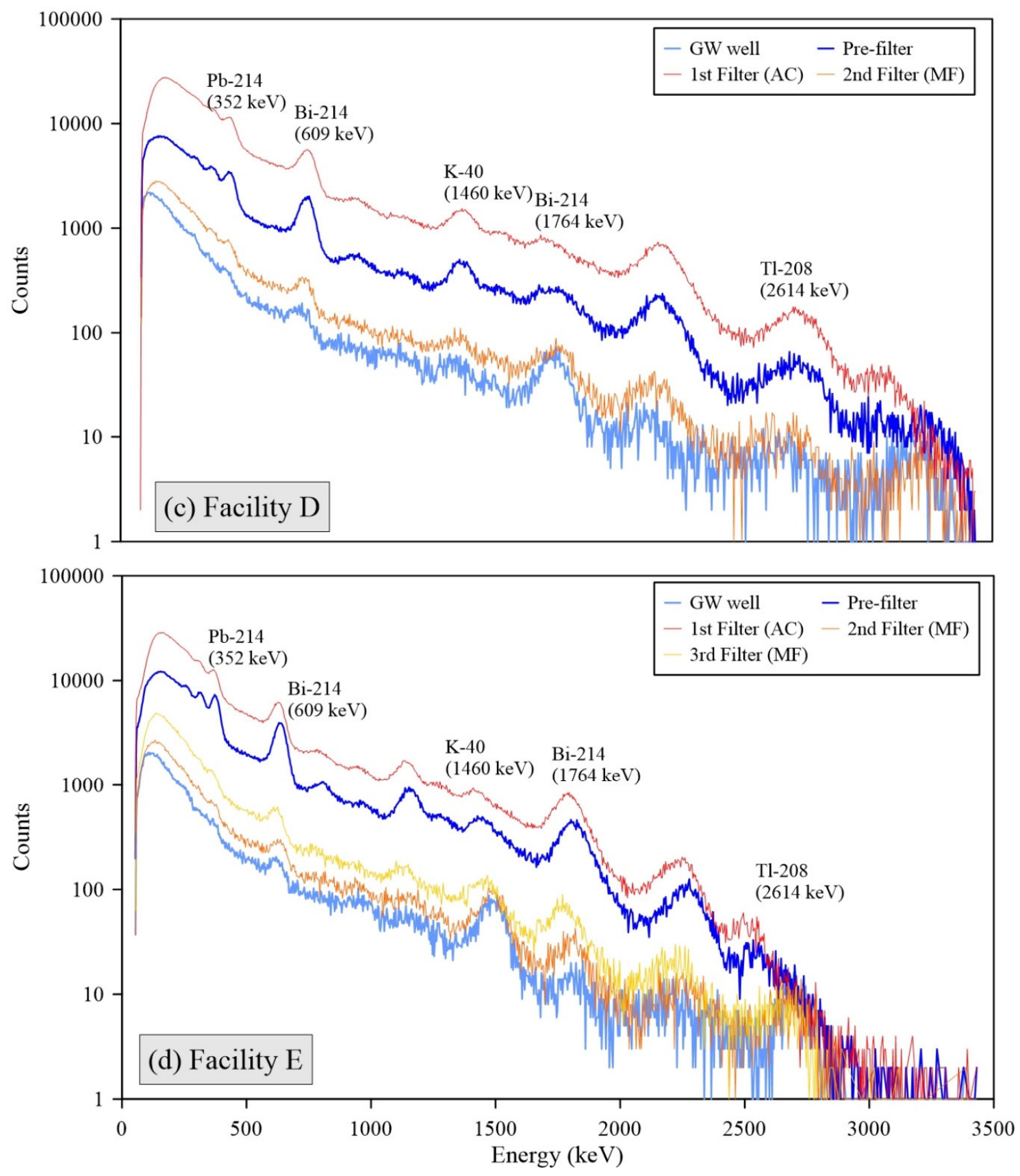

Figure 3. Spectra of radiation measured at the surface of individual filtering units: (a) Facility B, (b) Facility C, (c) Facility D, and (d) Facility E.

\subsection{Mechanism of NORM Accumulation into Filters}

Although numerous radionuclides are continuously generated by the radon decay processes in the water tanks, some of them were not observed due to their very short half-life (i.e., seconds or microseconds). Only radionuclides with half-lives of $\geq 20 \mathrm{~min}$, such as $\mathrm{Pb}-214\left(t_{1 / 2}=26.8 \mathrm{~min}\right)$ and Bi-214 $\left(t_{1 / 2}=19.9 \mathrm{~min}\right)$ were detected. These radon progenies migrated along with the water flow, and they fixed into the filter materials. It results in the increase of surface radioactivity dose rate on the FFs based on their gamma radiation, and the enrichment of $P b-210\left(t_{1 / 2}=22.2 \mathrm{yrs}\right)$ in the used filters. The predominant filter-accumulated NORMs, therefore, could be newly generated radionuclides during the water treatment processes, even considering that high concentrations of long-lived radionuclides, such as Th-234, Po-210, and total uranium, are observed in the used filters of some facilities (Figure 4). 


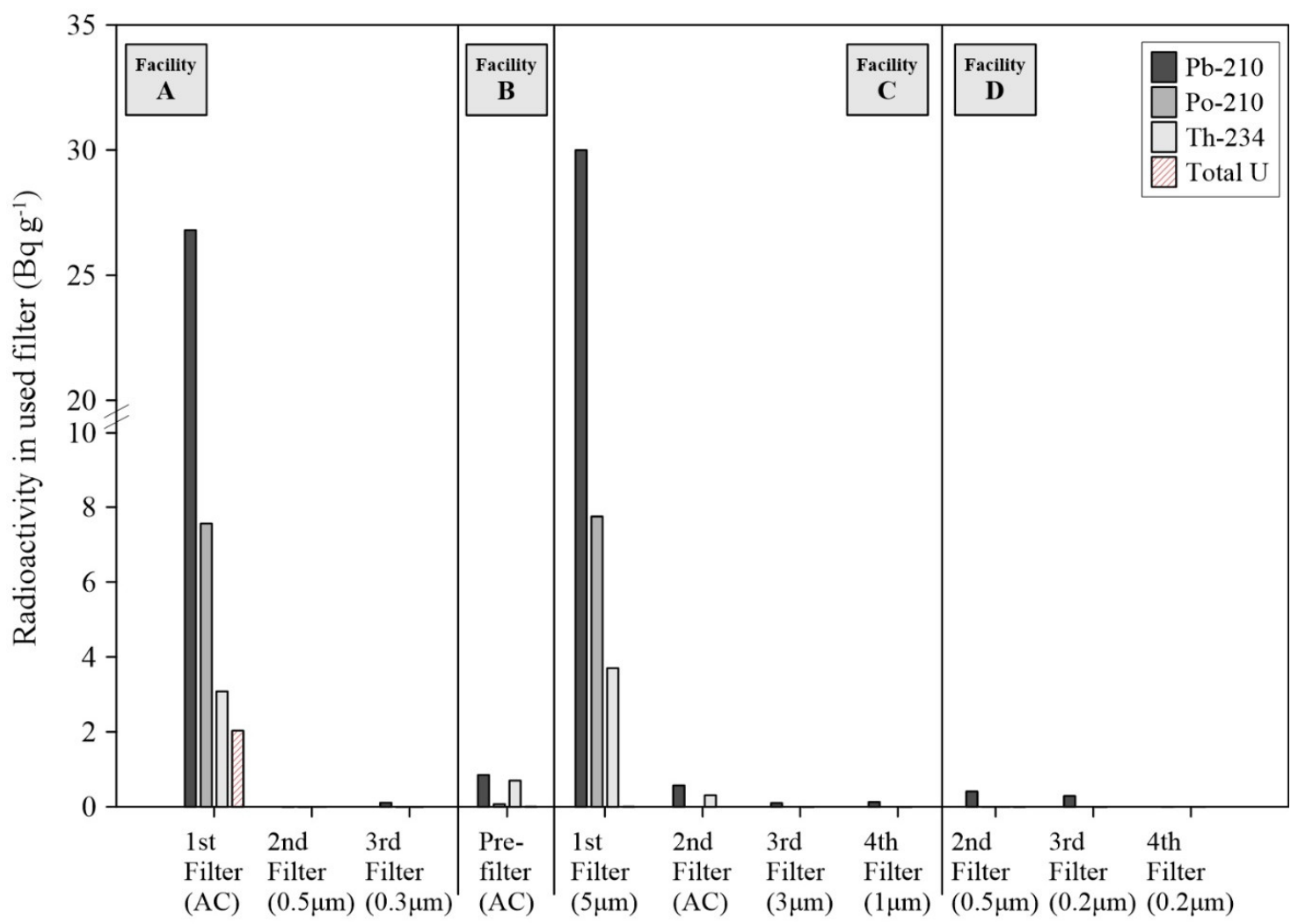

Figure 4. The measured radioactivity and concentrations of remaining radionuclides in the used filters.

The fouling that is formed by fine particles such as sediments and rock fragments in the groundwater can affect the accumulation of NORMs in the filters. Relatively large particles are removed by pre-filters placed before the water tanks, but not for all (ultra)fine sediments. The dark-colored fouling layers were frequently observed in the used FF filters (e.g., Figure S2 in the Supplementary Materials). These fouling materials could be negatively charged because they are mainly derived from fine silty and clayey sedimentation in the groundwater environment [27]. Most radon progenies, including $\mathrm{Pb}-214, \mathrm{Bi}-214$, and $\mathrm{Pb}-210$, are likely to act as cations in the groundwater because they are the post-transition metals. The electrostatic attractions between the radionuclides and fouling materials enhance the accumulation of NORMs into the FFs. In particular, high concentrations of NORMs in the used MFs could be strongly associated with the migration and fixation of fine particles, based on their low sorption affinities for radionuclides [18] unlike the AC materials (e.g., C facility in Figure 4).

\subsection{Estimated Radiological Risk}

The modified inverse square law was utilized to evaluate the potential radiological risk for the workers that operate the water treatment facilities inside the bottled-mineral-water facilities. Assuming that they work at a $1 \mathrm{~m}$ distance from the filter housings, the surface radiation dose rates decreased approximately 100 times than the dose rates measured at a $0.1 \mathrm{~m}$ distance (Table S1 in the Supplementary Materials). The observed highest radiation dose rate was $0.053 \mu \mathrm{Sv} \mathrm{h}^{-1}$ at the housing of ACF in the facility E. It increased significantly up to $52.5 \mu \mathrm{Sv} \mathrm{yr}^{-1}$ under the assumption of the average 4 hours-a-day and 250 days-a-year work near the filter equipment, but this is still low compared to the public dose limit (i.e., $1 \mathrm{mSv} \mathrm{yr}^{-1}$ ). Nevertheless, the potential radiological risk should be properly managed in case of direct and/or close handling of the used filters during the filter replacement. 
Additionally, the radiological risk was evaluated for workers at the filter disposal sites based on the measurements of radioactivity and estimation of annual amount for the used filters. The computed radiation dose rates exhibited extremely low levels because most of the trapped radionuclides in the filters were short-lived so that they are collapsed during transport processes to disposal sites (Table S2 in the Supplementary Materials). The remains of long-lived radionuclides have typically low levels of gamma constant (e.g., $6.5 \times 10^{-7}$ for Pb-210, $1.4 \times 10^{-9}$ for Po-210, and $2.9 \times 10^{-6} \mathrm{mSv} \mathrm{m}^{2} \mathrm{~h}^{-1} \mathrm{MBq}^{-1}$ for Th-234) compared to the short-lived radionuclides (e.g., $4.3 \times 10^{-5}$ for $\mathrm{Pb}-214$, and $2.1 \times 10^{-4} \mathrm{mSv} \mathrm{m}^{2} \mathrm{~h}^{-1} \mathrm{MBq}^{-1}$ for Bi-214) [25]. Even though there appeared to be no radiological effects on the disposal sites' workers, they need to be monitored depending on the filter waste amount and loading method in the disposal sites (e.g., huge filter wastes used in several mineral water treatment facilities are concentrated to one disposal site).

\section{Conclusions}

This study determines the accumulation mechanism for naturally occurring radioactive material (NORM) in the filters that are utilized for the production of bottled mineral water and evaluates the potential radiological risk for workers in the water treatment facilities. The short-lived radon progenies significantly influence high surface dose rates and filter accumulation, especially the FFs encountered immediately after leaving the water storage tanks, regardless of filter types. The ACFs can physicochemically uptake the aqueous-phase radionuclides, while the physical fouling is the important accumulation mechanism for the MF materials. Although the external radiation from the filters appears to be rarely harmful to the workers in the bottled-water production facilities, the radiological risk must be monitored and managed, especially near the water tanks and FFs.

As concluding remarks, there are a few suggestions to properly manage the radiological risk in the bottled-mineral-water facilities. Firstly, ventilation should be installed at the top of water storage tanks to reduce the radon concentrations and radon progenies' generation inside the tank. Secondly, the installation of pre-filters between the groundwater wells and water tanks is recommended to minimize the fouling effects in the FFs. These pre-filters and FFs, if needed, should be replaced with new filters more frequently than current replacement cycles. All the above suggestions will help prevent the accumulation of short-lived radionuclides in the FFs. Additionally, the translocation of pre-filters, water tanks, and FFs to a separate well-controlled building could contribute to lower the potential radiological risk to workers by decreasing their radiation exposure time and frequency. We expect that these suggestions can be applied to the numerous bottled-mineral-water facilities around the world, based on similar filtering processes using groundwater.

Supplementary Materials: The following are available online at http://www.mdpi.com/2073-4441/12/4/930/s1, Description: Summary Information for individual bottled mineral-water facilities, Figure S1: Mineral-water purifying processes at the individual bottled mineral water facilities, Figure S2: Cross section of membrane filters along treatment processes at the $\mathrm{C}$ facility, Table S1: Calculated effective dose at the bottled mineral-water facilities under estimated scenario ( $1 \mathrm{~m}$ distance) and extreme scenario ( $0.2 \mathrm{~m}$ distance), Table S2:. Calculated effective dose at the waste disposal site under estimated scenario $(1 \mathrm{~m}$ distance) and extreme scenario $(0.2 \mathrm{~m}$ distance).

Author Contributions: Conceptualization, S.C. and B.-U.C.; methodology, W.S., J.-H.H. and S.C.; formal analysis, J.-H.H.; investigation, W.S. and S.C.; data curation, J.J.; writing-original draft preparation, W.S.; writing-review and editing, J.J., S.C., and B.-U.C.; supervision, S.C. All authors have read and agreed to the published version of the manuscript.

Funding: This research was funded by grants from "Establishment of Technical Basis for Implementation on Safety Management for Radiation in the Natural Environment" of the Korea Institute of Nuclear Safety, and the "Analytical Study on Radioactive Materials" of the Korea Basic Science Institute (Grant no. C39709).

Conflicts of Interest: The authors declare no conflict of interest. 


\section{References}

1. Dragović, S.D.; Janković-Mandić, L.J.; Dragović, R.M.; Dordević, M.M.; Dokić, M.M. Spatial distribution of the 226Ra activity concentrations in well and spring waters in Serbia and their relation to geological formations. J. Geochem. Explor. 2012, 112, 206-211. [CrossRef]

2. Skeppström, K.; Olofsson, B. Uranium and radon in groundwater. Eur. Water 2007, 17, 51-62.

3. Smedley, P.L.; Smith, B.; Abesser, C.; Lapworth, D. Uranium Occurrence and Behaviour in British Groundwater; British Geological Survey: Nottingham, UK, 2006.

4. Stalder, E.; Blanc, A.; Haldimann, M.; Dudler, V. Occurrence of uranium in Swiss drinking water. Chemosphere 2012, 86, 672-679. [CrossRef]

5. Shin, W.; Oh, J.; Choung, S.; Cho, B.-W.; Lee, K.-S.; Yun, U.; Woo, N.-C.; Kim, H.K. Distribution and potential health risk of groundwater uranium in Korea. Chemosphere 2016, 163, 108-115. [CrossRef] [PubMed]

6. Vinson, D.S.; Vengosh, A.; Hirschfeld, D.; Dwyer, G.S. Relationships between radium and radon occurrence and hydrochemistry in fresh groundwater from fractured crystalline rocks, North Carolina (USA). Chem. Geol. 2009, 260, 159-171. [CrossRef]

7. Asaduzzaman, K.; Mannan, F.; Khandaker, M.U.; Farook, M.S.; Elkezza, A.; Amin, Y.M.; Sharma, S. Natural radioactivity levels in commercialized bottled drinking water and their radiological quality assessment. Desalin. Water Treat. 2016, 57, 11999-12009. [CrossRef]

8. Kim, Y.S.; Park, H.S.; Kim, J.Y.; Park, S.K.; Cho, B.W.; Sung, I.H.; Shin, D.C. Health risk assessment for uranium in Korean groundwater. J. Environ. Radioact. 2004, 77, 77-85. [CrossRef]

9. Rožmarić, M.; Rogić, M.; Benedik, L.; Štrok, M. Natural radionuclides in bottled drinking waters produced in Croatia and their contribution to radiation dose. Sci. Total Environ. 2012, 437, 53-60. [CrossRef]

10. Baeza, A.; Salas, A.; Guillén, J.; Muñoz-Serrano, A. Association of naturally occurring radionuclides in sludges from Drinking Water Treatment Plants previously optimized for their removal. Chemosphere 2014, 97, 108-114. [CrossRef]

11. Lytle, D.A.; Sorg, T.; Wang, L.; Chen, A. The accumulation of radioactive contaminants in drinking water distribution systems. Water Res. 2014, 50, 396-407. [CrossRef]

12. Palomo, M.; Penalver, A.; Aguilar, C.; Borrull, F. Presence of Naturally Occurring Radioactive Materials in sludge samples from several Spanish water treatment plants. J. Hazard. Mater. 2010, 181, 716-721. [CrossRef] [PubMed]

13. Fonollosa, E.; Nieto, A.; Peñalver, A.; Aguilar, C.; Borrull, F. Presence of radionuclides in sludge from conventional drinking water treatment plants. A review. J. Environ. Radioact. 2015, 141, 24-31. [CrossRef]

14. Chmielewska, I.; Chałupnik, S.; Bonczyk, M. Natural radioactivity in drinking underground waters in Upper Silesia and solid wastes produced during treatment. Appl. Radiat. Isot. 2014, 93, 96-100. [CrossRef]

15. Mulas, D.; Camacho, A.; Serrano, I.; Montes, S.; Devesa, R.; Duch, M.A. Natural and artificial radionuclides in sludge, sand, granular activated carbon and reverse osmosis brine from a metropolitan drinking water treatment plant. J. Environ. Radioact. 2017, 177, 233-240. [CrossRef]

16. Martínez, J.; Peñalver, A.; Baciu, T.; Artigues, M.; Danús, M.; Aguilar, C.; Borrull, F. Presence of artificial radionuclides in samples from potable water and wastewater treatment plants. J. Environ. Radioact. 2018, 192, 187-193. [CrossRef] [PubMed]

17. World Health Organization (WHO). Guidelines for Drinking-Water Quality, 4th ed.; WHO: Geneva, Switzerland, 2011.

18. Montaña, M.; Camacho, A.; Serrano, I.; Devesa, R.; Matia, L.; Vallés, I. Removal of radionuclides in drinking water by membrane treatment using ultrafiltration, reverse osmosis and electrodialysis reversal. J. Environ. Radioact. 2013, 125, 86-92. [CrossRef] [PubMed]

19. Shin, W.; Choung, S.; Han, J.H.; Han, W.S.; Jeon, S.; Ryu, J.S.; Chang, B.U. Accumulation of naturally occurring radioactive materials on the filters utilized in bottled mineral-water facilities. Appl. Geochem. 2017, 85, 154-161. [CrossRef]

20. Robbins, J.A.; Edgington, D.N. Determination of recent sedimentation rates in Lake Michigan using Pb-210 and Cs-137. Geochim. Cosmochim. Acta 1975, 39, 285-304. [CrossRef]

21. Enders, A.; Lehmann, J. Comparison of Wet-Digestion and Dry-Ashing Methods for Total Elemental Analysis of Biochar. Commun. Soil Sci. Plant Anal. 2012, 43, 1042-1052. [CrossRef] 
22. Mester, Z.; Sturgeon, R.E. Sample Preparation for Trace Element Analysis; Elsevier: Amsterdam, The Netherlands, 2003; Volume 41, ISBN 0-444-51101-6.

23. Minamoto, G.; Takeuchi, E.; Tadokoro, S. Estimation of ground surface radiation sources from dose map measured by moving dosimeter and 3D map. IEEE Int. Conf. Intell. Robot. Syst. 2014, 1889-1895.

24. Siegel, J.A.; Marcus, C.S.; Sparks, R.B. Calculating the absorbed dose from radioactive patients: The line-source versus point-source model. J. Nucl. Med. 2002, 43, 1241-1244. [PubMed]

25. Delacroix, D.; Guerre, J.P.; Leblanc, P.; Hickman, C. Radionuclide and radiation protection data handbook 2002. Radiat. Prot. Dosimetry 2002, 98, 1. [CrossRef] [PubMed]

26. European Commission. Radiation Protection 122 Practical Use of the Concepts of Clearance and Exemption(Part II); European Communities: Luxembourg, 2002; ISBN 9289433159.

27. Gwon, E.M.; Yu, M.J.; Oh, H.K.; Ylee, Y.H. Fouling characteristics of NF and RO operated for removal of dissolved matter from groundwater. Water Res. 2003, 37, 2989-2997. [CrossRef]

(C) 2020 by the authors. Licensee MDPI, Basel, Switzerland. This article is an open access article distributed under the terms and conditions of the Creative Commons Attribution (CC BY) license (http://creativecommons.org/licenses/by/4.0/). 